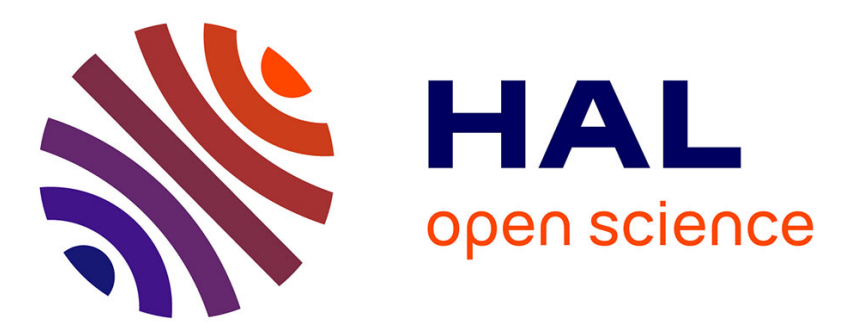

\title{
Alginate/Chitosan Compact Polyelectrolyte Complexes: A Cell and Bacterial Repellent Material
}

Thida Phoeung, Maria Vittoria Spanedda, Emilie Roger, Béatrice Heurtault, Sylvie Fournel, Andreas Reisch, Angela Mutschler, Fabienne Perrin-Schmitt, Joseph Hemmerle, Dominique Collin, et al.

\section{To cite this version:}

Thida Phoeung, Maria Vittoria Spanedda, Emilie Roger, Béatrice Heurtault, Sylvie Fournel, et al.. Alginate/Chitosan Compact Polyelectrolyte Complexes: A Cell and Bacterial Repellent Material. Chemistry of Materials, 2017, 29 (24), pp.10418-10425. 10.1021/acs.chemmater.7b03863 . hal-02142349

\section{HAL Id: hal-02142349 \\ https://hal.science/hal-02142349}

Submitted on 21 Dec 2021

HAL is a multi-disciplinary open access archive for the deposit and dissemination of scientific research documents, whether they are published or not. The documents may come from teaching and research institutions in France or abroad, or from public or private research centers.
L'archive ouverte pluridisciplinaire HAL, est destinée au dépôt et à la diffusion de documents scientifiques de niveau recherche, publiés ou non, émanant des établissements d'enseignement et de recherche français ou étrangers, des laboratoires publics ou privés. 


\title{
Alginate/Chitosan Compact Polyelectrolyte Complexes: A Cell and Bacterial Repellent Material
}

\author{
Thida Phoeung, ${ }^{\dagger,}$ Maria Vittoria Spanedda, ${ }^{\dagger}$ Emilie Roger, ${ }^{\dagger}$ Béatrice Heurtault, ${ }^{\dagger}$ Sylvie Fournel, ${ }^{\dagger}$
} Andreas Reisch, ${ }^{\S}$ Angela Mutschler, ${ }^{\ddagger}$ Fabienne Perrin-Schmitt, ${ }^{\ddagger}$ Joseph Hemmerle, ${ }^{\ddagger}$ Dominique Collin," Michel Rawiso," Fouzia Boulmedais, $\|$ Pierre Schaaf, ${ }^{*},+, \|$ Philippe Lavalle, ${ }^{\ddagger}$ and Benoît Frisch ${ }^{*}{ }^{\dagger}$

†Université de Strasbourg, CNRS, Laboratoire de Conception et Application de Molécules Bioactives UMR 7199, Faculté de Pharmacie, 74 route du Rhin 67401, Illkirch Cedex, France

${ }^{\ddagger}$ INSERM UMR 1121 Biomaterials and Bioengineering, Institut National de la Santé et de la Recherche Médicale, Université de Strasbourg, Faculté Dentaire de Strasbourg, Fédération de Médecine Translationnelle de Strasbourg, 11, Rue Humann 67085, Strasbourg Cedex, France

${ }^{\S}$ Faculté de Pharmacie, Laboratoire de Biophotonique et Pharmacologie, UMR 7213 CNRS/Université de Strasbourg, 74 route du Rhin 67401, Illkirch Cedex, France

"Institut Charles Sadron, CNRS UPR 22, 23 rue du Loess 67034, Strasbourg Cedex, France

Supporting Information

ABSTRACT: Ultracentrifugated compact polyelectrolyte
complexes (uCoPECs) represent a new class of materials
that are obtained by ultracentrifugation of solutions of
polyanion/polycation complexes in the presence of salt. In
the present study, two polysaccharides, chitosan and alginate,
were used to form such complexes, thus providing a solid
material uniquely composed of polysaccharides. The con-
ditions for obtaining the uCoPEC material were optimized: the
optimal salt concentration and polysaccharide concentrations
were assessed, and the ultracentrifugation speed proved to be a
key parameter to obtain compact and homogeneous materials. The Young's modulus, E, of the material was of the order of 12

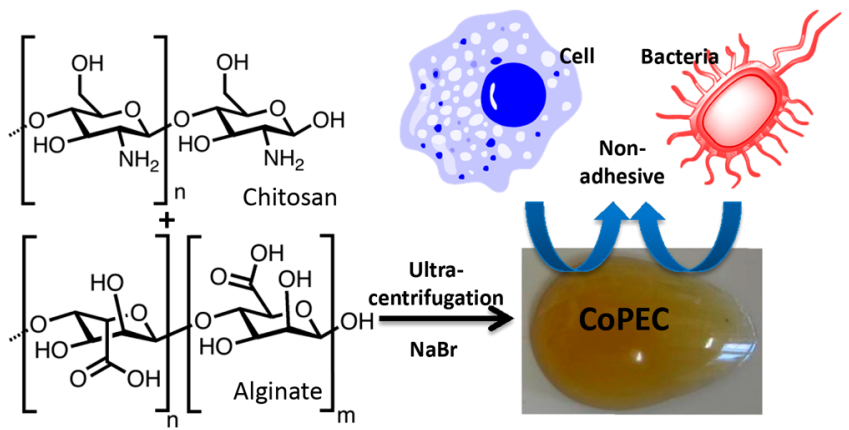
$\mathrm{MPa}$, which is the highest $E$ value measured for a uCoPEC. The material contained nanometer-sized crystals of chitosan as indicated by X-ray diffraction. Most strikingly, this material proves to be totally cell- and bacteria-resistant. Immunological tests show that this uCoPEC does not induce any proinflammatory response. This makes it a suitable candidate for the development of biocompatible and antifouling biomaterials composed only of polysaccharides.

\section{INTRODUCTION}

Mixing polyanions and polycations in solution leads usually to the formation of polyelectrolyte complexes. Such complexes form two phases, one poor and one rich in polyelectrolytes. The rich phase, called polyelectrolyte coacervate, is composed of loosely associated chains and possesses liquid-like properties. Polyelectrolyte coacervates have received considerable attention since their introduction in 1929 by Bungenberg de Jong and Kruyt. ${ }^{1}$ Their applications can be found in particular in medicine for drug encapsulation or in the food industry. On the other hand, when water is removed from polyanion/polycation solutions, the result is a stiff opaque material that is often difficult to handle. This is certainly the reason why these materials were ignored for a long time by the scientific community. In the mid sixties, Michaels and coworkers found a way to circumvent this drawback by adding cosolutes and using salts that plasticize the polyanion/polycation material. In a pioneering paper, Michaels enumerated numerous potential applications of these kind of novel materials. ${ }^{2}$ Yet, his work remained fairly unnoticed until 2009 when Schlenoff introduced compact polyelectrolyte complexes (CoPEC) that he also called saloplastic materials. ${ }^{3} \mathrm{He}$ showed that by ultracentrifuging polystyrenesulfonate/poly(diallyldimethylammonium) (PSS/PDADMA) complexes in the presence of high concentrations of salt, a new type of material can be obtained whose mechanical properties are close to that of the nucleus pulposus of an intervertebral disk. Soon after, he showed that such materials can also be obtained by extrusion processes. ${ }^{4}$ Using the system poly(acrylic acid)/ poly(allylamine) (PAA/PAH), we found that CoPECs can also possess very interesting properties such as high ultimate tensile strain (up to $400 \%$ ), ${ }^{5}$ self-healing properties, ${ }^{6}$ and embedding enzymes into the material confers an enzymatic activity. ${ }^{7}$ In the CoPEC, the enzymatic activity is even protected and enhanced 
when compared to that of pure enzyme. Recently, Mano and coworkers proposed another method to prepare compact saloplastic membranes by centrifugation of polyelectrolyte complexes (and not ultracentrifugation) followed by water evaporation. He applied his method to chitosan/alginate ${ }^{8}$ and more recently to chitosan/chondroitin sulfate. ${ }^{9}$ Even if called compact saloplastic, these materials have different properties from those obtained by ultracentrifugation. Up to now, ultracentrifuged CoPECs (uCoPEC) were obtained only with synthetic polyelectrolytes. ${ }^{3,5,6}$ Here, we present a new type of uCoPEC entirely constituted of polysaccharides chitosan (CHI) and alginate (ALG). This material displays properties which are entirely different from those of the material obtained by Mano and coworkers: ${ }^{9}$ it possesses the remarkable biological property to be cell- and bacteria-repellent surfaces.

\section{EXPERIMENTAL SECTION}

Materials. Alginic acid sodium salt (ALG) and fluorescein isothiocyanate isomer I (FITC, 90\%) were purchased from Aldrich. Chitosan (average molecular weight 250000 , viscosity $30-100 \mathrm{cP}$, deacetylation degree $>90 \%$ ) was obtained from Glentham Life Sciences. Sodium bromide ( $\mathrm{NaBr}, 99 \%)$, hydrochloric acid $(\mathrm{HCl}$, $37 \%)$, and acetic acid (99.8\%) were obtained from Sigma-Aldrich. Sodium hydroxide $(\mathrm{NaOH}, 99 \%)$ was purchased from Carlo Erba. All molecules were used as received. Milli-Q water (18 M $\Omega$, Millipore) was used in all experiments.

CoPECs Preparation. Alginate and chitosan solution concentrations were varied from 10 to $1.25 \mathrm{mg} \cdot \mathrm{mL}^{-1}$. $\mathrm{NaBr}$ content was varied from 1.5 to $0 \mathrm{M}$. For alginate solutions, alginate was first dissolved in pure milli- $\mathrm{Q}$ water. Then, the $\mathrm{pH}$ was adjusted to 6.5 by adding a certain amount of acetic acid and $\mathrm{NaBr}$ was added to the desired concentration. For chitosan solutions, chitosan was added to milli-Q water and a certain amount of acetic acid was added to obtain the complete dissolution of chitosan. The $\mathrm{pH}$ was then adjusted to 4.5 by adding $\mathrm{NaOH}$ and $\mathrm{NaBr}$ to the solution at the desired concentration.

To obtain the CoPEC, first, alginate and chitosan macromolecules were complexed together by mixing equal volumes of alginate and chitosan solutions (having the same concentrations). Mixing was performed by pumping both solutions using a peristaltic pump (Ismatec IPC 9329, flow rate $=45 \mathrm{rpm}$ ). Reactions were stirred with a magnetic stir bar at $200 \mathrm{rpm}$. Then, complex suspensions were transferred into Falcon centrifuge tubes (BD) and centrifuged at $9400 \mathrm{~g}$ using a 12169-h rotor type (Sigma Laboratory Centrifuges 4K15C) at $20{ }^{\circ} \mathrm{C}$ for $15 \mathrm{~min}$. Finally, precompact complexes were transferred into polycarbonate thick-wall centrifuge tubes (Beckman Coulter Inc. Brea, $\mathrm{CA}$, United States) with their supernatant and ultracentrifuged from $34000 \mathrm{~g}$ to $308000 \mathrm{~g}$ using a $90 \mathrm{Ti}$ rotor type at $23{ }^{\circ} \mathrm{C}$ for $12 \mathrm{~h}$ to obtain the CoPECs. There were samples that after ultracentrifugation could not be removed from the centrifuge tubes because they fell apart. Those that could be removed and cut into slices without falling apart are called handable.

Water Content Measurement. Water content of CoPECs was determined by a Mettler Toledo HS153 halogen moisture analyzer. Samples from three different preparations were first dehydrated for storage and rehydrated in PBS for $16 \mathrm{~h}$ before measurements.

Rheology Measurements. For rheological testing, $150 \mu \mathrm{m}$-thick slices (length: $1 \mathrm{~cm}$, width: $1 \mathrm{~cm}$ ) of CoPECs were obtained using a cryostat (IP 3919). For each CoPEC, 3 slices were obtained and equilibrated in PBS buffer ( $\mathrm{pH}$ 7.4) for several days before mechanical tests. To characterize the mechanical behavior of CoPECs, shear measurements were performed at $25{ }^{\circ} \mathrm{C}$ in a plate-plate geometry with the sample in contact with the PBS buffer ( $\mathrm{pH}$ 7.4). The apparatus used is a piezorheometer which is a plate-plate strain rheometer that uses piezoelectric ceramics vibrating in the shear mode. ${ }^{5}$ This instrument allows one to acquire data in a wide domain of frequency ranging from $20 \mathrm{mHz}$ to $3 \mathrm{kHz}$.
X-ray Scattering. Small angle X-ray scattering experiments were performed by using a diffractometer developed by Molecular Metrology (Elexience, France) that uses a Rigaku Micromax 007HF generator with a copper-rotating anode. The wavelength of the incident X-ray beam is $\lambda=1.54 \AA$. The diffractometer operates with a pinhole collimation of the X-ray beam focused by a multilayer optic designed by Osmic and a two-dimensional gas-filled multiwire detector. The sample to detector distance was set at $0.7 \mathrm{~m}$, leading to a range of scattering vectors covered by the experiment $0.01<q<$ $0.32 \AA^{-1}$. The scattering vector $q$ is defined by $q=(4 \pi / \lambda) \sin (\theta / 2)$, where $\lambda$ is the wavelength of the incident beam and $\theta$ is the scattering angle. The $q$-resolution related to the beam size on the sample and the beam divergence was close to $0.005 \AA^{-1}$. Cells of $1 \mathrm{~mm}$ thickness and calibrated Mica windows were used as sample holders. The effective thicknesses of the swollen or wet films that were maintained in these cells were, however, unknown and less than $1 \mathrm{~mm}$. Measurements were performed at room temperature. Wide-angle X-ray scattering experiments were carried out from the same diffractometer by using Phosphor imaging plates from Molecular Dynamics as detectors. These plates were set at $0.06 \mathrm{~m}$ from the samples, allowing us to explore scattering vectors ranging from $q=0.05$ to $3.5 \AA^{-1}$. The same cells of $1 \mathrm{~mm}$ thickness and Mica windows were used as sample holders. Measurements were performed at room temperature. For small-angle X-ray scattering (SAXS), all data were treated according to standard procedures for isotropic SAXS. After radial averaging, the spectra were corrected from electronic noise of the detector, empty cell, absorption, and sample thickness. A ${ }^{55} \mathrm{Fe}$ source was used for the corrections of geometrical factors and detector cells efficiency as well as a silver behenate sample for the $q$-calibration. The normalization to the unit incident flux was then obtained using water or Lupolen as standard samples. Nevertheless, such measurements on an absolute scale have not been achieved for the wide-angle X-ray scattering experiments. The spectra were then locked onto the related SAXS ones. After all these data treatments, the scattered intensities were corrected from the scattering of the solvent. This last correction was done through the far-away point method, which assumes that the density fluctuations are almost identical for the background and the film. The background is therefore obtained from the scattered intensity of the solvent, which is modified by a constant factor (simple multiplication or addition in log representation) to be superimposed to the scattered intensity of the film at high $q$ values $\left(q>0.6-0.8 \AA^{-1}\right)$, i.e. in a $q$-range where the concentration fluctuations are negligible. Here, this was the case for $q>1.5 \AA^{-1}$. According to such a procedure, the scattered intensity $I(q)$ containing all the structural information was obtained for each film.

Cell Culture, Attachment, and Growth. One-hundred and fifty $\mu$ m-thick CoPEC slices (about $12 \mathrm{~mm}$ in diameter), stored in $1 \mathrm{M}$ $\mathrm{NaBr}$ at $\mathrm{pH} 4.5$, were equilibrated to $\mathrm{pH} 7.4$ for $3 \times 1 \mathrm{~h}$. Then were incubated for $3 \mathrm{~h}$ in sterile phosphate buffered solution (PBS, Gibco), followed by 2 successive 30 min UV irradiations (recto and verso) for sterilization. uCoPEC slices were prevented to float in culture media and maintained at the bottom of culture wells by UV sterilized inox cylinders of $10 \mathrm{~mm}$ inner diameter fitting culture wells. uCoPEC slices were then equilibrated for about $3 \mathrm{~h}$ by incubation in cell culture medium. Then cell suspensions were added in assay and control wells. Three cell types were probed, namely murine MC3T3-E1 preosteoblasts, NIH-3T3 fibroblasts, and human SW480 colorectal adenocarcinoma cells, all provided from American Type Culture Collection (ATCC, United States: ATCC CRL-2593, ATCC CRL-1658, and ATCC CCL-228, respectively). Preosteoblasts, fibroblasts, and colorectal adenocarcinoma cells were seeded respectively at $10^{3}, 5 \times$ $10^{3}$, and $5 \times 10^{4}$ cells onto $\mathrm{uCoPEC}$ and sterile glass cover slides in wells of 24-well plates. One milliliter of MEM alpha medium for MC3T3-E1 cells and DMEM medium at 4.5 g glucose for NIH-3T3 and SW480 cells was added in wells, both fully supplemented with 100 $\mathrm{U} / \mathrm{mL}$ penicillin, $100 \mathrm{U} / \mathrm{mL}$ streptomycin, $10 \%$ fetal bovine serum from Gibco. Cultures were done in a humidified $37{ }^{\circ} \mathrm{C}, 5 \% \mathrm{CO}_{2}$ environment. Cell growth was followed by phase contrast observation, and cultures were stopped as soon as $80 \%$ confluence was reached in control wells to avoid losses of unattached cells in assays and controls. 
Images of several field views have been taken from each sample with an optical inverted microscope (Nikon TIE microscope equipped with a 40 PL DL PH2 (0.65 NA) objective and an Andor Zyla sCMOS camera). Then, cells were fixed and processed for standard basic immunohistochemistry to assess the number and morphology of attached cells. Phalloidine-rhodamine labeling (PhaI, \#77418-1EA, Sigma-Aldrich) at $0.005 \mathrm{mg} \cdot \mathrm{mL}^{-1}$ final concentration revealed cytoskeleton actin-F filaments and Vectashield DAPI-containing mounting medium (\#H-1200, Cliniscience) allowed nuclei visualization, imaging, and counting.

Bacterial Tests. Staphylococcus aureus (S. aureus, ATCC 25923) strains were used to test the behavior of the uCoPECs with respect to bacteria. Bacterial strains were cultured aerobically at $37{ }^{\circ} \mathrm{C}$ in a Mueller Hinton Broth (MHB) medium (Merck, Germany), pH 7.4. One colony was transferred to $10 \mathrm{~mL}$ of MHB medium and incubated at $37{ }^{\circ} \mathrm{C}$ for $20 \mathrm{~h}$. To obtain bacteria in the mid logarithmic phase of growth, the absorbance at $620 \mathrm{~nm}$ of overnight cultures was adjusted to 0.001 , corresponding to a final density of $8 \times 10^{5} \mathrm{CFU} \cdot \mathrm{mL}^{-1}$. After sterilization by using UV irradiations, uCoPECs were deposited in 24well plates with $300 \mu \mathrm{L}$ of $S$. aureus, $A_{620}=0.001$ and incubated during $24 \mathrm{~h}$ at $37{ }^{\circ} \mathrm{C}$. A control was performed with a $S$. aureus solution in contact with glass slides, with and without antibiotics. After $24 \mathrm{~h}$ of contact, the bacterial quantity was determined by measuring the absorbance of the supernatant at $620 \mathrm{~nm}$.

To evaluate the health of the bacteria which are on the uCoPEC or glass slide surfaces, the BacLight RedoxSensor CTC Vitality (ThermoFisher Scientific Inc., France) was used. This kit provides effective reagents for evaluating bacterial health and vitality. The kit contains 5-cyano-2,3-ditolyl tetrazolium chloride (CTC), which has been used to evaluate the respiratory activity of $S$. aureus. Healthy bacteria will absorb and reduce CTC into an insoluble, red fluorescent formazan product. Bacteria which are dead or with slow respiratory activity will not reduce CTC and consequently will not produce red fluorescent product. Finally, this kit gives semiquantitative estimate of healthy vs unhealthy bacteria. SYTO 24 green-fluorescent nucleic acid stain (ThermoFisher Scientific Inc., France) was used for visualizing all bacteria. Each sample was washed with phosphate-buffered saline buffer, pH 7.4 (PBS). Then, $270 \mu \mathrm{L}$ of PBS and $30 \mu \mathrm{L}$ of CTC/SYTO 24 solution were added. The samples were incubated $30 \mathrm{~min}$ at $37^{\circ} \mathrm{C}$, away from light. Each surface was observed by confocal microscopy (Zeiss LSM 710 microscope, Germany) using a $63 \times$ objective immersed in oil. Excitation/emission wavelength of stains was $450 /$ $630 \mathrm{~nm}$ for CTC and $490 / 515 \mathrm{~nm}$ for SYTO 24.

Preparation of COPEC Microparticles. Alginate/chitosan CoPEC was placed in PBS $1 \times$ for at least $48 \mathrm{~h}$. The complex was then dried with a wipe, cut in small portions, and freeze-dried overnight. The resulting solid was crushed in a mortar and passed through a $300 \mu \mathrm{m}$ sieve.

Cytokine Production Assay. RAW 264-7 cells (ATCC, United States: ATCC ${ }^{\mathrm{R}}$ TIB-71) were cultured in RPMI 1640 supplemented with $10 \%$ FCS (fetal calf serum), streptomycin $(10 \mu \mathrm{g} / \mathrm{mL})$, and penicillin $(100 \mathrm{U} / \mathrm{mL})$ at $10^{4}$ cells $/$ well in a 96 -well microplate in the presence of microparticles of CoPECs $(<300 \mu \mathrm{m}$ diameter $)$ at concentration ranging from 0.5 to $500 \mu \mathrm{g} / \mathrm{mL}$ or with LPS (0.5 to 2 $\mu \mathrm{g} / \mathrm{mL}$ ) as positive control. After 16 and $48 \mathrm{~h}$, supernatants were collected, and concentrations of IL-6 were evaluated by ELISA. Commercially available ELISA reagents were used to evaluate concentrations of IL-6 (Ready-SET-Go, eBioscience, San Diego, $\mathrm{CA}$ ). All procedures were performed following the manufacturer's instructions. Results were expressed as cytokine concentration in pg. $\mathrm{mL}^{-1}$. The detection limit was $4 \mathrm{pg} \cdot \mathrm{mL}^{-1}$ for IL-6.

\section{RESULTS AND DISCUSSION}

Build-Up Conditions. We processed CHI/ALG uCoPECs by mixing $\mathrm{CHI}$ and ALG solutions of equal concentrations and equal salt concentrations, both at $\mathrm{pH} 4.5$, then centrifuging the solution a first time at $9400 \mathrm{~g}$ and further ultracentrifuging (between 9400 and $308000 g$ ) the precompacted complexes. The weak electrostatic interactions between polysaccharides narrows the range of process conditions allowing to obtain handable uCoPECs when compared to those made of synthetic polyelectrolytes. We first observed that by using $\mathrm{NaCl}$ as salt over a large range of concentrations extending up to saturation, we could not obtain a handable material, whereas this was possible with $\mathrm{NaBr}$. Next, we assessed the effect of the $\mathrm{NaBr}$ concentration on the uCoPEC formation. $\mathrm{NaBr}$ concentration was varied from 0 to $1.5 \mathrm{M}$ while the concentrations of both alginate and chitosan solutions were kept at $2.5 \mathrm{mg} \cdot \mathrm{mL}^{-1}(\mathrm{pH}$ 4.5) and the ultracentrifugation speed was fixed at $157000 \mathrm{~g}$. At $0,0.15$, and $1.5 \mathrm{M} \mathrm{NaBr}$, the uCoPECs were white, opaque, and brittle. At $0.5 \mathrm{M} \mathrm{NaBr}$, the uCoPECs were yellow and handable but remained heterogeneous, whereas at $1.0 \mathrm{M}$ they became handable and more transparent.

Such a window effect of the salt concentration on the formation of CoPECs was already observed for other systems. ${ }^{5}$ It was explained by the fact that the CoPEC formation is mainly dependent upon two processes: precipitation (reaction 1) and salt doping (reaction 2):

$$
\begin{aligned}
& \mathrm{Pol}^{+} \mathrm{Br}^{-}{ }_{\text {aq }}+\mathrm{Pol}^{-} \mathrm{Na}^{+} \text {aq } \\
& \rightarrow \mathrm{Pol}^{+} \mathrm{Pol}_{\mathrm{s}}^{-}+\mathrm{Na}^{+}{ }_{\text {aq }}+\mathrm{Br}^{-}{ }_{\text {aq }} \\
& \rightarrow \text { precipitation }
\end{aligned}
$$

$$
\begin{aligned}
& \mathrm{Pol}^{+} \mathrm{Pol}_{\mathrm{s}}^{-}+\mathrm{Na}_{\text {aq }}^{+}+\mathrm{Br}^{-}{ }_{\mathrm{aq}} \\
& \rightarrow \mathrm{Pol}^{+} \mathrm{Br}^{-}{ }_{\text {aq }}+\mathrm{Pol}^{-} \mathrm{Na}^{+}{ }_{\mathrm{aq}} \\
& \rightarrow \text { salt doping }
\end{aligned}
$$

where $\mathrm{Pol}^{+}$and $\mathrm{Pol}^{-}$represent the cationic and anionic groups of the polyelectrolytes respectively, aq means aqueous phase, and $s$ means solid phase. ${ }^{5}$ At low salt concentration, during the polyanion/polycation complex formation, the counterions are released from the polyelectrolyte backbones, leading to a direct interaction between the anionic and cationic groups of the polyelectrolytes (reaction 1). This results in a material that contains few $\mathrm{Na}^{+}$or $\mathrm{Br}^{-}$ions. However, it is known that the counterions play the role of plasticizer. At low salt concentration, the material is thus brittle. On the other hand, at too high salt concentrations, doping dominates; at extreme salt concentrations, the number of $\mathrm{Pol}^{+} \mathrm{Pol}^{-}$interactions becomes extremely small, and the material is no longer compact. For intermediate salt concentrations (in our case, 0.5 and $1 \mathrm{M} \mathrm{NaBr}$ ), the balance between precipitation and doping reactions leads to a processable and handable material. Next, we assessed the effect of the polysaccharide concentrations on the $\mathrm{uCoPEC}$ formation. We always kept the concentrations of ALG and $\mathrm{CHI}$ equal. The concentrations were decreased from 10 to $1.25 \mathrm{mg} \cdot \mathrm{mL}^{-1}$; the $\mathrm{NaBr}$ concentration was fixed to $1 \mathrm{M}$, and the ultracentrifugation speed fixed at $157000 \mathrm{~g}$. While decreasing the polyelectrolyte concentration, the uCoPECs became more transparent. At $10 \mathrm{mg} \cdot \mathrm{mL}^{-1}$ the material was brittle. The brittleness decreased as the polyelectrolyte concentration decreased. At concentrations of $1.25 \mathrm{mg} \cdot \mathrm{mL}^{-1}$, the material was handable. Thus, this concentration was selected for all the following experiments. We did not explore lower concentrations because the amount of material that is processed decreases when the concentration is decreased.

Finally, we investigated the effect of the ultracentrifugation speed. The materials were prepared starting from solutions of 1 $\mathrm{M} \mathrm{NaBr}, 1.25 \mathrm{mg} \cdot \mathrm{mL}^{-1}$ of $\mathrm{CHI}$ at $\mathrm{pH} 4.5$ and $1.25 \mathrm{mg} \cdot \mathrm{mL}^{-1}$ of 


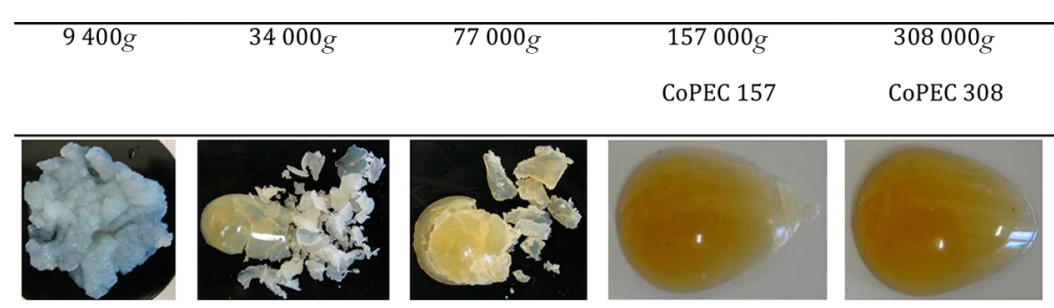

Figure 1. Typical alginate/chitosan samples obtained for the different centrifugation speeds $\left(1 \mathrm{M} \mathrm{NaBr}, 1.25 \mathrm{mg} \cdot \mathrm{mL}^{-1}\right.$ of $\mathrm{CHI}$ at $\mathrm{pH} 4.5$ and 1.25 $\mathrm{mg} \cdot \mathrm{mL}^{-1}$ of ALG at $\mathrm{pH} 6.5$ ). Image sizes are $2 \times 2 \mathrm{~cm}^{2}$.

ALG at $\mathrm{pH}$ 6.5. The centrifugation speed was varied from $9400 \mathrm{~g}$ to $308000 \mathrm{~g}$. At $9400 \mathrm{~g}$, the CHI/ALG complexes that formed in solution aggregated after mixing resulting in a brittle, white, opaque, and unhandable material. Pictures of the obtained uCoPECs are given in Figure 1. At $34000 \mathrm{~g}$ and $77000 \mathrm{~g}$, the uCoPEC started to be more compact, still opaque, brittle, and unhandable. At $157000 \mathrm{~g}$ and $308000 \mathrm{~g}$, it became compact, transparent, and handable. To further observe the effect of the ultracentrifugation speed on the structural properties of the uCoPECs, we performed scanning electron microscopy on slices of the uCoPECs corresponding to $157000 \mathrm{~g}$ and $308000 \mathrm{~g}$ (see Figure 1 of the Supporting Information). It can be observed that at $157000 \mathrm{~g}$, the material is not perfectly homogeneous with areas of small porosity and others of higher porosity. At $308000 \mathrm{~g}$, the material has become homogeneous and more compact. This speed was selected for the remaining studies. We determined the water content of these CoPECs and found a water content of $59.3( \pm 4.8) \%$ for CoPEC 157 and $45.9( \pm 2.5) \%$ for CoPEC 308. This water content is to be compared to water contents of typical CHI/ ALG complex materials which lie between 70 and $97 \%$ of water depending on the preparation and composition. ${ }^{10,11}$

Rheological Properties. After ultracentrifugation at $308000 \mathrm{~g}$, the materials were cut perpendicularly to the centrifugation tube into fine slices of constant thickness using a cryostat. These slices were used for determination of the materials rheological properties using a piezo-rheometer. Figure 2 presents the overall measurements of the elastic modulus $G^{\prime}$ and the loss modulus $G^{\prime \prime}$ performed as a function of the frequency for three different slices.

All three slices resulted in the same values of $G^{\prime}$ and $G^{\prime \prime}$, indicating that the uCoPEC obtained at this ultracentrifugation

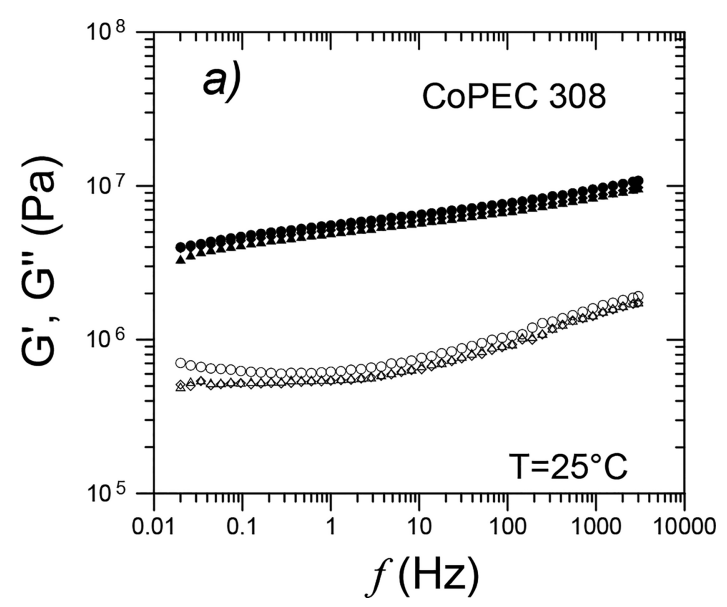

Figure 2. $G^{\prime}$ (filled symbols) and $G^{\prime \prime}$ (open symbols) corresponding to three slices of an uCoPEC obtained at $308000 \mathrm{~g}$, hydrated in PBS. speed was homogeneous (this was not the case for uCoPECs obtained at $157000 \mathrm{~g}$, where the $G^{\prime}$ and $G^{\prime \prime}$ values depended upon the location of the slice cut out of the material). The $G^{\prime}$ value is always much higher than $G^{\prime \prime}$ with a very little frequency dependence of $G^{\prime}$ and $G^{\prime \prime}$ over a wide frequency range. This plateau-like behavior of $G^{\prime}$ and $G^{\prime \prime}$ is qualitatively similar to the behavior observed at low frequency for some polymer physical gels. ${ }^{12}$ In our case, the physical junctions between chains are formed by ion pairs between negative carboxylic groups of alginate and positive amine groups of chitosan. The rheological behavior of our CHI/ALG uCoPECs is very different from that of the so far reported uCoPECS: PSS/PDADMA, ${ }^{3}$ PMAA/ PDADMA, ${ }^{3}$ and PAA/PAH. ${ }^{5}$ First, the only CoPEC showing a low frequency elastic plateau reported so far is PSS/PDADMA, which is composed of strong synthetic polyelectrolytes. The value of the shear elastic modulus obtained for this uCoPEC was around $1 \mathrm{kPa}$. For PAA/PAH and PMAA/PDADMA uCoPECs, which are composed of weak synthetic polyelectrolytes, no elastic plateau has been found in the same range of frequency. ${ }^{3,5}$ Second, all of these uCoPECs exhibit a viscoelastic behavior of the Rouse type $\left(G^{\prime} \approx G^{\prime \prime} \approx \omega^{0.5}\right)$ for different ranges of frequency: $10-100 \mathrm{rad} / \mathrm{s}$ for PSS/PDADMA; 2-20 rad/s for PMAA/PDADMA (stoichiometric ratio $=1$ ). ${ }^{3}$ In our ALG/ $\mathrm{CHI}$ system, the complex shear modulus exhibits a behavior different than that of the uCoPECs previously discussed. For all the frequencies studied, the mechanical response is always of the solid type $\left(G^{\prime}>G^{\prime \prime}\right)$ with a $G^{\prime}$-plateau at low frequency characterized by an extremely high value $\left(G^{\prime} \approx 4 \times 10^{6} \mathrm{~Pa}\right)$. This value, which is located in between that of the rubbery plateau and that of the glassy plateau for amorphous polymer melts, suggests the presence of crystallinities in our samples. In fact, crystalline domains act like hard particles trapped in the polyelectrolytes melt and enable the low frequency elastic plateau value to overcome that of the rubbery plateau. Similar results were already reported in the literature in the case of strongly flocculated physical gels and polymer composites. ${ }^{13,14}$ In our uCoPECs, crystallinity is probably linked to the chemical nature of alginate and chitosan. The presence of crystalline domains in our samples was confirmed by X-ray scattering data.

To compare the mechanical strength of the ALG/CHI CoPEC with other biomaterials, we assume that the $G^{\prime}$-value obtained at low frequency for the ALG/CHI CoPEC is close to the static shear modulus. We also assume that the sample is isotropic. Under these conditions, we can deduce the Young's modulus value from the relationship $E=2 \mathrm{G}(1+\nu)$, where $\nu$ is the Poisson's ratio and $G$ is the limit of $G^{\prime}$ when $\omega$ goes to 0 . By assuming that $\nu=0.5$ in agreement with the value deduced from the measurements of $E$ and $G$ performed on other CoPECs, ${ }^{15,16}$ the value of the Young's modulus for ALG/CHI CoPEC can be estimated at about $12 \mathrm{MPa}$. Our piezo-rheology method used to determine the Young's modulus was validated by comparison with stress-strain experiments performed on 
Table 1. Young's Modulus of Different CoPECs, Biomaterials Composed of Natural Macromolecules, and Biological Systems ${ }^{a}$

\begin{tabular}{|c|c|c|c|c|c|}
\hline composition & sample type & porosity & testing method & $E$ (Young's modulus) & ref \\
\hline $\mathrm{ALG} / \mathrm{CHI}$ & CoPEC & nonporous & rheology & $12 \mathrm{MPa}$ & present work \\
\hline $\mathrm{PAA} / \mathrm{PAH}$ & CoPEC & porous & rheology & no plateau & 5 \\
\hline PSS/PDADMA & CoPEC & porous & rheology & $3 \mathrm{kPa}$ & 3 \\
\hline PMMA/PDADMA & CoPEC & porous & rheology & no plateau & 3 \\
\hline $\mathrm{CHI}$ & gel & $\mathrm{Ni}$ & tension & $6 \mathrm{MPa}$ & 20 \\
\hline $\mathrm{CHI}$ & gel & nonporous & tension & $5-7 \mathrm{MPa}$ & 18 \\
\hline $\mathrm{CHI}$ & gel & porous & tension & $0.1-0.5 \mathrm{MPa}$ & 18 \\
\hline $\mathrm{CHI} /$ gelatin & gel & $\mathrm{Ni}$ & tension & $1.2 \mathrm{MPa}$ & 20 \\
\hline ALG/CHI/Glut & PEMs films & $\mathrm{Ni}$ & microbalance & $2 \mathrm{MPa}$ & 19 \\
\hline $\mathrm{ALG} / \mathrm{Ca}^{2+}$ & gel & $\mathrm{Ni}$ & longitudinal deformation, rheology & $120 \mathrm{kPa}$ & 29 \\
\hline articular cartilage & & & indentation, compression & $0.3-0.9 \mathrm{MPa}$ & 22,23 \\
\hline epidermis & & & tension & $9 \mathrm{MPa}$ & 25 \\
\hline Achilles tendon & & & tension & $300 \mathrm{MPa}$ & 28 \\
\hline osteoid calcified matrix & & & compression & $1 \mathrm{MPa}$ & 24 \\
\hline bone tissues & & & tension & $4-20 \mathrm{GPa}$ & 25,26 \\
\hline
\end{tabular}

other materials. ${ }^{17}$ For comparison, Table 1 lists Young's moduli values reported in the literature for the different reported uCoPECs for biomaterials composed of natural macromolecules and for biological systems. For biomaterials, only systems in the gel state composed of either CHI and/or ALG are listed. ${ }^{18-20}$ All of these systems presented $E$-values lower than the one obtained for ALG/CHI uCoPEC, even when they are cross-linked, like ALG/CHI-cross-linked with glutaraldehyde. In biological systems, mammalian organs have $E$-values between $100 \mathrm{~Pa}$ to $10 \mathrm{kPa}^{21}$ However, some biological tissues present high Young's modulus such as cartilage, ${ }^{22,23}$ osteoid calcified matrix, ${ }^{24}$ bone tissues, ${ }^{25,26}$ skin layers, ${ }^{27}$ or tendons. ${ }^{28}$ These materials present $E$-values in the MPa range and can reach $20 \mathrm{GPa}$ (bone tissue). The Young's modulus of the $\mathrm{CHI} /$ ALG uCoPEC is higher than the osteoid calcified matrix (giving rigid bone $)^{24}$ and is of the same order of magnitude as the epidermis, one of the skin layers (see Table 1). ${ }^{25}$

X-Ray Scattering Experiments. Using X-ray scattering experiments, we analyzed the structure of our uCoPECs (Figure 3). The $\mathrm{X}$-ray profile in Figure 3 displays three successive maxima or Bragg peaks in the $q$-range $0.5<q<1.5$ $\AA^{-1}$. The amplitude of these maxima is rather small. Correlatively, the peaks are rather broad. However, they reveal the existence of small crystallites, i.e. the existence of some translation order. One can point out that orientational order (nematic nonoriented domains) would not lead to three successive maxima. From the width of these maxima, accounting for the experimental resolution, an average crystallite size or grain size of $6 \mathrm{~nm}$ can be estimated from the Scherrer formula. ${ }^{30}$

The distances associated with the successive maxima peaks are $10.6 \AA\left(q=0.61 \AA^{-1}\right), 6.16 \AA\left(q=1.02 \AA^{-1}\right)$, and $4.65 \AA(q$ $\left.=1.35 \AA^{-1}\right)$. The positions of the first and third maxima in our $\mathrm{X}$-ray data are close to those of the two main peaks reported in the literature for the chitosan. ${ }^{31}$ This suggests the presence of small crystals (average diameter $6 \mathrm{~nm}$ ) due to chitosan within a chitosan/alginate matrix, chitosan being known to be a semicrystalline polymer whose degree of crystallinity depends on its degree of deacetylation. The crystallinity is maximal for $0 \%$ (also known as chitin) or $100 \%$ of deacetylation, and a minimum of crystallinity is found for intermediate deacetylation. ${ }^{18}$ When mixing for example $85 \%$ of pure deacetylated chitosan with gelatin, a $20 \%$ of crystallinity was shown. The

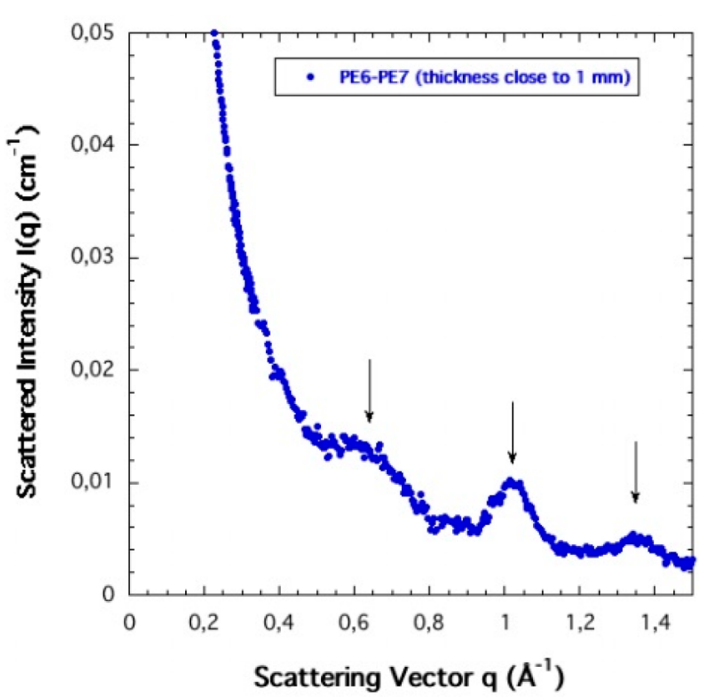

Figure 3. X-ray scattering profile of a uCoPEC slide in the small- and wide-angle domains suggesting the existence of a translational order, i.e. crystallites. The maxima of the three peaks correspond respectively to distances of $10.6,6.16$, and $4.65 \AA$.

crystallinity level decreased up to $4 \%$ when adding up to $80 \%$ of gelatin and was amorphous for higher levels of gelatin. ${ }^{20}$

Cellular Adhesion. Next, we evaluated the behavior of eukaryotic cells in contact with our uCoPEC. Three cell types were assessed for adherence and cytotoxicity tests: murine NIH-3T3 fibroblasts, murine MC3T3-E1 preosteoblasts, and human SW480 colorectal adenocarcinoma. The cell suspensions in culture medium were added into wells containing uCoPECs or glass slides (control). Whereas all three cell types adhered and grew on glass slides after three days, presenting the typical morphologies of their cell type (Figure 4, left), the cells remained floating in the medium above the uCoPEC with occasionally partial adherence with unphysiological roundshaped cell conglomerates (Figure 4, right).

When flushed with pure medium, the cells were removed from the surface, demonstrating their weak adhesion on the uCoPECs. Any enzymology viability test (such as MMT or $\mathrm{LDH}$ protocols) would have been relevant in this case. We only did a labeling with DAPI and rhodamine-phalloidin to observe the nucleus and the cytosquelette (actin) respectively. On the 

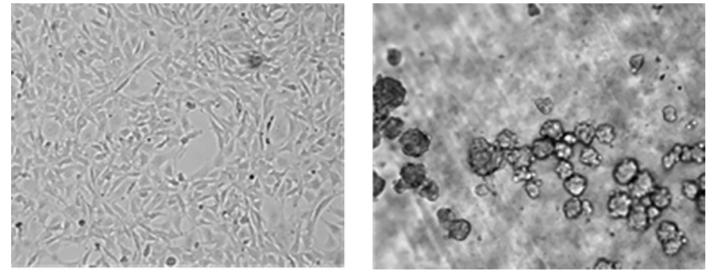

Figure 4. Contrast phase microscopy images of murine fibroblasts NIH3T3 cells, growing and spread on glass (left) but aggregated and quiescent on uCoPEC slice (right). Image sizes are $260 \times 200 \mu \mathrm{m}^{2}$. Similar observations were performed with murine MC3T3-E1 preosteoblasts and human SW480 colorectal adenocarcinoma.

uCoPECs, the few attaching cells were rounded shaped (Figure 5) and did not appear necrotic or apoptotic cells. The
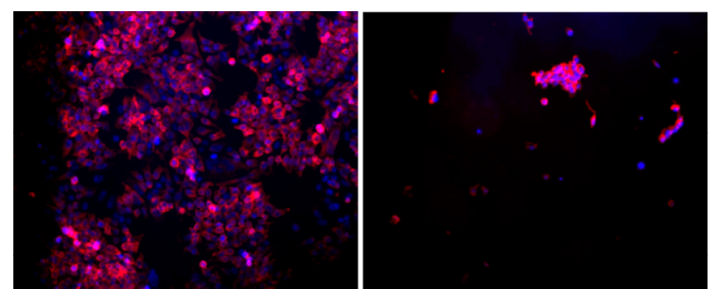

Figure 5. DAPI-labeled DNA (blue) and rhodamine-phalloidin labeled actin-F filaments (red) in human SW480 colorectal adenocarcinoma cells after three days culture on glass (left) and on an uCoPEC slice (right). Image sizes are $450 \times 370 \mu \mathrm{m}^{2}$.

noncytotoxicity was assessed by two additional controls: (i) by culturing cells on a glass substrate surrounding a uCoPEC disc and (ii) by taking the supernatant in contact with a CoPEC for seven days and then by adding it on cells seeded on a glass substrate. In both experiments, cell growth was normal regarding adhesion and proliferation (data not shown).

Cell adhesion experiments were also performed in the absence of serum in culture medium (to prevent protein adsorption on the uCoPEC) and by adsorbing a collagen layer (from a $0.5 \mathrm{mg} \cdot \mathrm{mL}^{-1}$ solution) on the $\mathrm{uCoPEC}$ before cell seeding. Collagen was selected because it is usually used to functionalize surfaces and to promote cell adhesion.

Yet, all these experiments resulted in an absence of cell adhesion for the three cell types. Thus, CHI/ALG uCoPEC appears as a material that totally prevents cell adhesion.

Immunological Response. Next, we evaluated the immune response of cells in contact with uCoPECs. To evaluate the proinflammatory effect, RAW 264-7 (murine macrophage cell line) cells were cultured with uCoPEC in the form of microparticles ( $<300 \mu \mathrm{m}$ diameter) during 16 and $48 \mathrm{~h}$. Cell supernatants were then collected, and the production of the two proinflammatory cytokines IL-6 (Figure 6) and TNF- $\alpha$ (see Figure 2 of Supporting Information) were evaluated by ELISA. Lipopolysaccharide (LPS), known to induce proinflammatory cytokine production when cultured with RAW cells, was used as positive control. As shown in Figure 6, chitosan alone triggered only a weak production of IL- 6 and TNF- $\alpha$ for the highest concentration evaluated $\left(500 \mu \mathrm{g} \cdot \mathrm{mL}^{-1}\right)$, while alginate alone triggered cytokine production from $50 \mu \mathrm{g} \cdot \mathrm{mL}^{-1}$. When mixed together in solution, alginate and chitosan induced a response close to LPS, while the uCoPEC induced only a very weak proinflammatory response at very high concentrations. It thus appears that the interactions of both polymers in uCoPEC decreases strongly their proinflammatory effect compared to that of the same polymers in solution.

Bacterial Adhesion. We also tested the behavior of prokaryotic cells by measuring adhesion of $S$. aureus bacteria on the uCoPEC. For this purpose, slices of uCoPEC were immersed in a solution containing $8 \times 10^{5} \mathrm{CFU} \cdot \mathrm{ml}^{-1}$ in a growth medium for $24 \mathrm{~h}$. After this delay, the absorbance at 620 $\mathrm{nm}$ of the supernatant was determined, and the uCoPEC slices were rinsed with buffer.

We monitored a similar increase in the optical density of the supernatant in contact with the uCoPEC slice and a glass surface after $24 \mathrm{~h}$. This indicates that the uCoPEC do not inhibit bacterial growth in solution and have no bactericidal effect (Figure 7a).

Bacteria adhering on the uCoPEC surface after $24 \mathrm{~h}$ were treated with Syto24 (green fluorescence) and CTC (red fluorescence) to label bacteria. Only healthy bacteria should

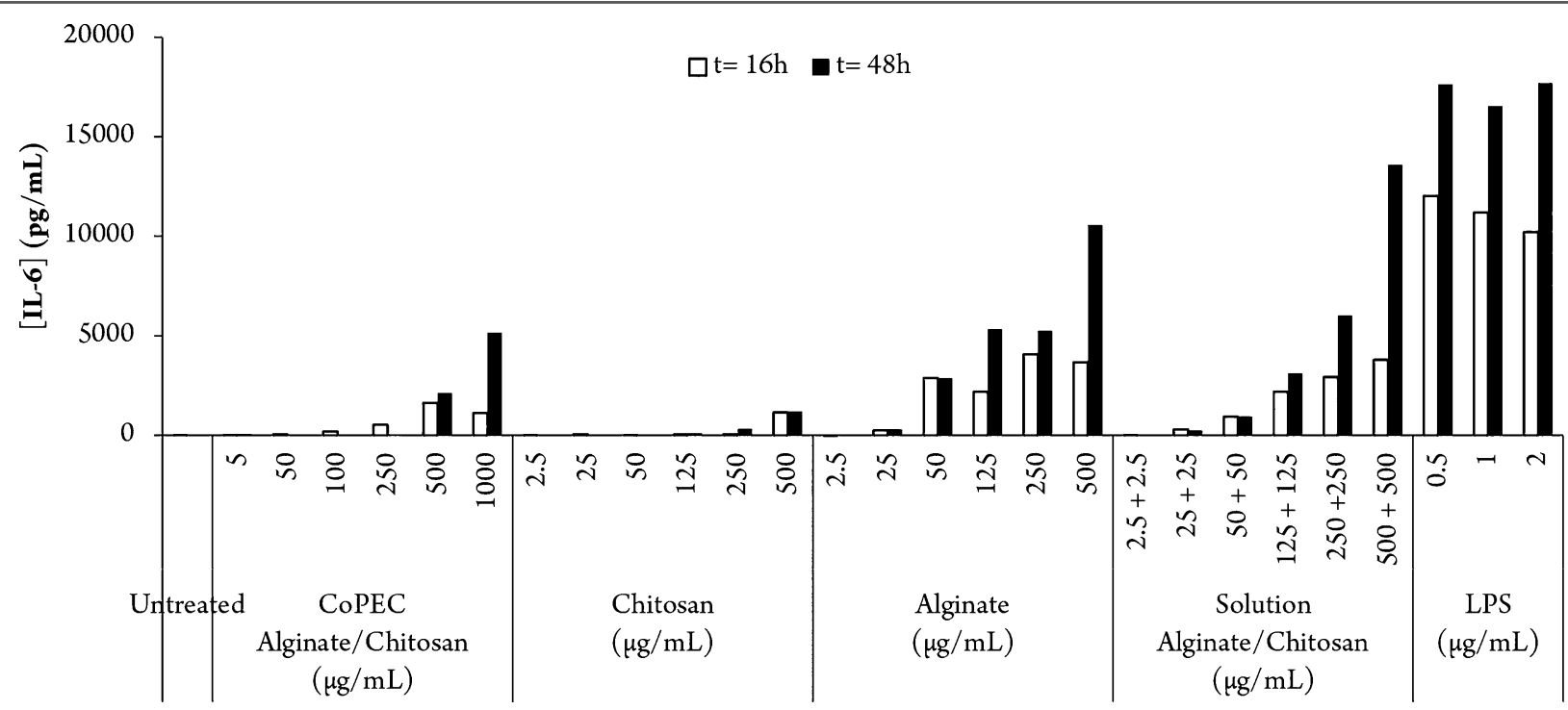

Figure 6. Production of interleukine 6 (IL-6) by RAW cells for alginate/chitosan uCoPEC, chitosan alone, alginate alone, a mixture of alginate and chitosan in solution, and LPS as positive control. 

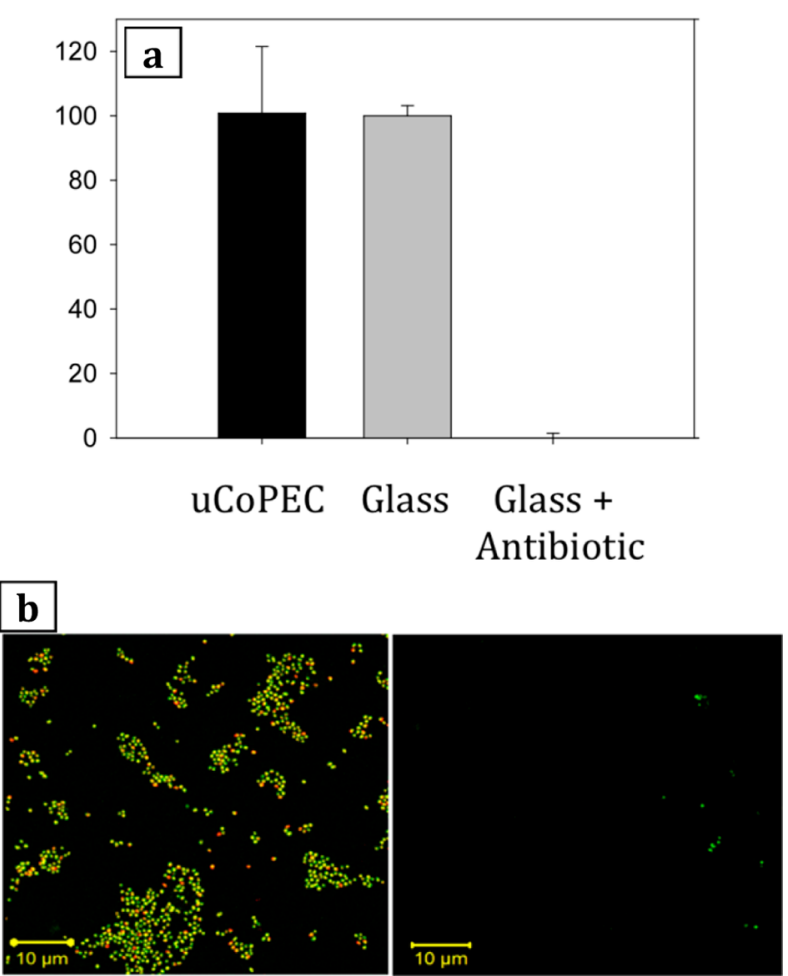

Figure 7. Normalized S. aureus growth (\%) in supernatant after $24 \mathrm{~h}$ in contact with uCoPEC, glass, and glass + antibiotics as control. Each value corresponds to the mean value of three samples per condition, and error bars correspond to standard deviations. (b, left) Control experiment on glass. (b, right) S. aureus remaining during $24 \mathrm{~h}$ in contact with uCoPEC with the bacterial suspension. In both cases, the bacteria were brought in contact with Syto24 (green) and CTC (red) markers to distinguish dead (green) from alive (yellow) bacteria.

produce red fluorescence, and green fluorescence was used for visualizing all bacteria. Microscopic observations of the surface show that almost no bacteria were adhered on the uCoPEC surface after $24 \mathrm{~h}$ of contact with the bacterial suspension (Figure $7 \mathrm{~b}$ ), whereas many bacteria grew on the control glass surface and appeared yellow (green + red) (Figure $7 \mathrm{~b}$, left), indicating that they were alive, as expected on the control surface. Only very few bacteria were present on the uCoPEC, and they appeared green, indicating that they were not alive (Figure $7 \mathrm{~b}$, right). This unexpected result indicates that our material is antifouling not only against eukaryotic cells but also against bacteria.

\section{CONCLUSIONS}

We showed that by ultracentrifuging alginate/chitosan complexes a material of unexpected properties was designed. In marked difference with previous materials composed of synthetic polyelectrolytes and obtained with similar processes, the CHI/ALG uCoPEC presents a higher Young's modulus estimated at $12 \mathrm{MPa}$ which lies in the range of biological tissues such as epidermis or bone tissues. With a material of such high modulus, it was expected that cells or bacteria would adhere, ${ }^{32-34}$ yet this was not the case. Our CHI/ALG uCoPEC appears strongly cell and bacteria repellent. One can notice that one finds in the literature CHI/ALG materials onto which cells adhere $^{35-37}$ and others onto which cells do not adhere ${ }^{38}$ or that do not adhere to tissues. ${ }^{39} \mathrm{Up}$ to now, one cannot predict the behavior of CHI/ALG materials with respect to cells, a question that should trigger further research in this field. The material appears also as non-proinflammatory. This is to be compared to CHI/ALG nanoparticles which were reported to be anti-inflammatory. ${ }^{40}$ These properties make this material of great potential for biomedical applications such as in the field of catheters or parietal implants that should not adhere to biological tissues. The next step will be to better understand the mechanisms involved in this unexpected behavior. Our material was obtained by ultracentrifugation but, as shown by Schlenoff, ${ }^{4}$ one can envision using extrusion to process such materials, which opens these materials toward a large range of applications.

\section{ASSOCIATED CONTENT}

Supporting Information

The Supporting Information is available free of charge on the ACS Publications website $: t \quad \ldots$ a a.

SEM images of CoPEC, preparation of fluorescent $\mathrm{CoPEC}$, and cytokine production assay results (PDF)

\section{AUTHOR INFORMATION}

\section{Corresponding Authors}

*E-mail: schaaf@unistra.fr.

*E-mail: frisch@unistra.fr.

\section{ORCID}

Angela Mutschler: 0000-0002-8226-977X

Fouzia Boulmedais: 0000-0002-4934-9276

Pierre Schaaf: 0000-0001-7423-5492

Philippe Lavalle: 0000-0001-8798-912X

Notes

The authors declare no competing financial interest.

\section{ACKNOWLEDGMENTS}

The authors gratefully acknowledge financial support from Université de Strasbourg and Centre National de la Recherche Scientifique (C.N.R.S.). F.B. and P.S. acknowledge the International Center for Frontier Research in Chemistry (Labex CSC, PSC 016)

\section{REFERENCES}

(1) Bungenberg de Jong, H. G.; Kruyt, H. R. Coacervation (Partial Miscibility in Colloidal Systems). Proc.K. Ned. Akad. Wet. 1929, 32, 849-856.

(2) Michaels, A. S. Polyelectrolyte Complexes. Ind. Eng. Chem. 1965, $57,32-40$.

(3) Porcel, C. H.; Schlenoff, J. B. Compact Polyelectrolyte Complexes: "Saloplastic" Candidates for Biomaterials. Biomacromolecules 2009, 10, 2968-75.

(4) Shamoun, R. F.; Reisch, A.; Schlenoff, J. B. Extruded Saloplastic Polyelectrolyte Complexes. Adv. Funct. Mater. 2012, 22, 1923-1931.

(5) Reisch, A.; Tirado, P.; Roger, E.; Boulmedais, F.; Collin, D.; Voegel, J.-C.; Frisch, B.; Schaaf, P.; Schlenoff, J. Compact Saloplastic Poly(Acrylic Acid)/Poly(Allylamine) Complexes: Kinetic Control over Composition, Microstructure, and Mechanical Properties. Adv. Funct. Mater. 2013, 23, 673-682.

(6) Reisch, A.; Roger, E.; Phoeung, T.; Antheaume, C.; Orthlieb, C.; Boulmedais, F.; Lavalle, P.; Schlenoff, J. B.; Frisch, B.; Schaaf, P. On the Benefits of Rubbing Salt in the Cut: Self-Healing of Saloplastic Paa/Pah Compact Polyelectrolyte Complexes. Adv. Mater. 2014, 26, 2547-51.

(7) Tirado, P.; Reisch, A.; Roger, E.; Boulmedais, F.; Jierry, L.; Lavalle, P.; Voegel, J.-C.; Schaaf, P.; Schlenoff, J.; Frisch, B. Catalytic 
Saloplastics: Alkaline Phosphatase Immobilized and Stabilized in Compacted Polyelectrolyte Complexes. Adv. Funct. Mater. 2013, 23, 4785-4792.

(8) Costa, R. R.; Costa, A. M. S.; Caridade, S. G.; Mano, J. F. Compact Saloplastic Membranes of Natural Polysaccharides for Soft Tissue Engineering. Chem. Mater. 2015, 27, 7490-7502.

(9) Rodrigues, M. N.; Oliveira, M. B.; Costa, R. R.; Mano, J. F. Chitosan/Chondroitin Sulfate Membranes Produced by Polyelectrolyte Complexation for Cartilage Engineering. Biomacromolecules 2016, $17,2178-2188$.

(10) Verma, D.; Desai, M. S.; Kulkarni, N.; Langrana, N. Characterization of Surface Charge and Mechanical Properties of Chitosan/Alginate Based Biomaterials. Mater. Sci. Eng., C 2011, 31, 1741-1747.

(11) Chen, T. W.; Chang, S. J.; Niu, G. C. C.; Hsu, Y. T.; Kuo, S. M. Alginate-Coated Chitosan Membrane for Guided Tissue Regeneration. J. Appl. Polym. Sci. 2006, 102, 4528-4534.

(12) Nijenhuis, E. R. Thermoreversible Networks - Viscoelastic Properties and Structure of Gels - Introduction. Adv. Polym. Sci. 1997, 130, 1-12.

(13) Larson, R. G. The Structure and Rheology of Complex Fluids; Oxford University Press: New York: 1999.

(14) Bangarusampath, D. S.; Ruckdaschel, H.; Altstadt, V.; Sandler, J. K. W.; Garray, D.; Shaffer, M. S. P. Rheology and Properties of MeltProcessed Poly(Ether Ether Ketone)/Multi-Wall Carbon Nanotube Composites. Polymer 2009, 50, 5803-5811.

(15) Jaber, J. A.; Schlenoff, J. B. Mechanical Properties of Reversibly Cross-Linked Ultrathin Polyelectrolyte Complexes. J. Am. Chem. Soc. 2006, 128, 2940-2947.

(16) Hariri, H. H.; Schlenoff, J. B. Saloplastic Macroporous Polyelectrolyte Complexes: Cartilage Mimics. Macromolecules 2010, 43, 8656-8663.

(17) Sanchez-Ferrer, A.; Rogez, D.; Martinoty, P. Influence of the Degree of Polymerisation and of the Architecture on the Elastic Properties of New Polyurea Elastomers. RSC Adv. 2015, 5, 67586770.

(18) Suh, J. K. F.; Matthew, H. W. T. Application of Chitosan-Based Polysaccharide Biomaterials in Cartilage Tissue Engineering: A Review. Biomaterials 2000, 21, 2589-2598.

(19) Alves, N. M.; Picart, C.; Mano, J. F. Self Assembling and Crosslinking of Polyelectrolyte Multilayer Films of Chitosan and Alginate Studied by Qcm and Ir Spectroscopy. Macromol. Biosci. 2009, $9,776-85$.

(20) Cheng, M.; Deng, J.; Yang, F.; Gong, Y.; Zhao, N.; Zhang, X. Study on Physical Properties and Nerve Cell Affinity of Composite Films from Chitosan and Gelatin Solutions. Biomaterials 2003, 24, 2871-80.

(21) Levental, I.; Georges, P. C.; Janmey, P. A. Soft Biological Materials and Their Impact on Cell Function. Soft Matter 2007, 3, 299-306.

(22) Korhonen, R. K.; Laasanen, M. S.; Toyras, J.; Rieppo, J.; Hirvonen, J.; Helminen, H. J.; Jurvelin, J. S. Comparison of the Equilibrium Response of Articular Cartilage in Unconfined Compression, Confined Compression and Indentation. J. Biomech. 2002, 35, 903-909.

(23) Freed, L. E.; Langer, R.; Martin, I.; Pellis, N. R.; VunjakNovakovic, G. Tissue Engineering of Cartilage in Space. Proc. Natl. Acad. Sci. U. S. A. 1997, 94, 13885-13890.

(24) Engler, A. J.; Sen, S.; Sweeney, H. L.; Discher, D. E. Matrix Elasticity Directs Stem Cell Lineage Specification. Cell 2006, 126, 677-689.

(25) Bayraktar, H. H.; Morgan, E. F.; Niebur, G. L.; Morris, G. E.; Wong, E. K.; Keaveny, T. M. Comparison of the Elastic and Yield Properties of Human Femoral Trabecular and Cortical Bone Tissue. J. Biomech. 2004, 37, 27-35.

(26) Rho, J. Y.; Kuhn-Spearing, L.; Zioupos, P. Mechanical Properties and the Hierarchical Structure of Bone. Med. Eng. Phys. 1998, 20, 92102.
(27) Tran, H. V.; Charleux, F.; Ehrlacher, A.; Ho Ba Tho, M. C. Propriétés Mécaniques Multi-Couches De La Peau Humaine in Vivo. National Symposium on struture calculation 2005, 1.

(28) Almeida-Silveira, M. I.; Lambertz, D.; Perot, C.; Goubel, F. Changes in Stiffness Induced by Hindlimb Suspension in Rat Achilles Tendon. Eur. J. Appl. Physiol. 2000, 81, 252-7.

(29) Draget, K. I.; Stokke, B. T.; Yuguchi, Y.; Urakawa, H.; Kajiwara, K. Small-Angle X-Ray Scattering and Rheological Characterization of Alginate Gels. 3. Alginic Acid Gels. Biomacromolecules 2003, 4, 16611668.

(30) Guinier, A. X-Ray Diffraction in Crystals, Imperfect Crystals and Amorphous Bodies; Dover: New York, 1994.

(31) Zhang, Y. Q.; Xue, C. H.; Xue, Y.; Gao, R. C.; Zhang, X. L. Determination of the Degree of Deacetylation of Chitin and Chitosan by X-Ray Powder Diffraction. Carbohydr. Res. 2005, 340, 1914-1917.

(32) Yeung, T.; Georges, P. C.; Flanagan, L. A.; Marg, B.; Ortiz, M.; Funaki, M.; Zahir, N.; Ming, W. Y.; Weaver, V.; Janmey, P. A. Effects of Substrate Stiffness on Cell Morphology, Cytoskeletal Structure, and Adhesion. Cell Motil. Cytoskeleton 2005, 60, 24-34.

(33) Schneider, A.; Francius, G.; Obeid, R.; Schwinte, P.; Hemmerle, J.; Frisch, B.; Schaaf, P.; Voegel, J. C.; Senger, B.; Picart, C. Polyelectrolyte Multilayers with a Tunable Young's Modulus: Influence of Film Stiffness on Cell Adhesion. Langmuir 2006, 22, $1193-1200$

(34) Discher, D. E.; Janmey, P.; Wang, Y. L. Tissue Cells Feel and Respond to the Stiffness of Their Substrate. Science 2005, 310, 11391143.

(35) Kong, Y.; Xu, R.; Darabi, M. A.; Zhong, W.; Luo, G. X.; Xing, M. M. Q.; Wu, J. Fast and Safe Fabrication of a Free-Standing Chitosan/ Alginate Nanomembrane to Promote Stem Cell Delivery and Wound Healing. Int. J. Nanomed. 2016, 11, 2543-2555.

(36) Silva, J. M.; Duarte, A. R.; Caridade, S. G.; Picart, C.; Reis, R. L.; Mano, J. F. Tailored Freestanding Multilayered Membranes Based on Chitosan and Alginate. Biomacromolecules 2014, 15, 3817-26.

(37) Jiang, C. L.; Wang, Z. L.; Zhang, X. Q.; Zhu, X. Q.; Nie, J.; Ma, G. P. Crosslinked Polyelectrolyte Complex Fiber Membrane Based on Chitosan-Sodium Alginate by Freeze-Drying. RSC Adv. 2014, 4, 41551-41560.

(38) Rodrigues, A. P.; Genari, S. C.; Paulo, N. M.; da Conceicao, M.; de Brito e Silva, M. S.; Moraes, A. M. Evaluation of Cell Growth Characteristics on Chitosan-Alginate Membranes to Assess Their Potential Application on Highly Exuding Skin Lesions and in Vivo Evaluation in Wounded Cat. Cells and Culture 2010, 4, 789-794.

(39) Chang, J. J.; Lee, Y. H.; Wu, M. H.; Yang, M. C.; Chien, C. T. Electrospun Anti-Adhesion Barrier Made of Chitosan Alginate for Reducing Peritoneal Adhesions. Carbohydr. Polym. 2012, 88, 13041312.

(40) Friedman, A. J.; Phan, J.; Schairer, D. O.; Champer, J.; Qin, M.; Pirouz, A.; Blecher-Paz, K.; Oren, A.; Liu, P. T.; Modlin, R. L.; Kim, J. Antimicrobial and Anti-Inflammatory Activity of Chitosan Alginate Nanoparticles: A Targeted Therapy for Cutaneous Pathogens. J. Invest. Dermatol. 2013, 133, 1231-1239. 